\title{
EFFECT OF THIAMINE TETRAHYDROFURFURYL DISULFIDE UPON THE INTESTINAL MOTILITY
}

\author{
TAKESI HUKUHARA, RYOZI NANBA AND HIROSI SIINA
}

\author{
Department of Physiology, Okayama Unizersity Medical \\ School, Okayama
}

(Received June 25, 1965)

\begin{abstract}
With regard to the influence of thiamine propyl disulfide (TPD) and thiamine tetrahydrofurfuryl disulfide (TTFD) upon the intestinal motility a series of experiments has been performed in our laboratory: Nanba and Nakayama (6) and Nakayama and Nanba (7) observed that on the anesthetized dogs these drugs stimulated the intestinal mucosa to elicit the mucosal intrinsic reflex, characteristic nature of which had been described by Hukuhara, Yamagami and Nakayama (1) and Hukuhara, Nakayama and Sumi (2). Furthermore, they showed that intravenous administration of the drugs produced a rise of tone and an increase of the amplitude of rhythmic contractions in the dog small intestine. The present experiments were performed to elaborate the results obtained in previous works, utilizing nonanesthetized dogs provided with three kinds of Thiry-Vella loops.
\end{abstract}

\section{EXPERIMENTAL}

\section{Methods}

The experiments were performed on three kinds of Thiry-Vella loops, each of which was a part of the jejunal segment of one and the same dog. One loop was a normal one with both the intramural ganglion cells and extrinsic nerves intact, another one, the decentralized one with ganglion cells intact but the mesenteric nerves distributing to it severed, and the last loop, an aganglionic one, its intramural ganglion cells being completely destroyed by the complete anemia method devised by Hukuhara, Sumi and Kotani (3) and Hukuhara, Kotani and Sato (4) and additionally decentralized. The loops were estimated at about $25 \mathrm{~cm}$ in length, respectively, in the beginning of the operation. The experiments were performed during the period ranging 60 through 350 days after the operation, intermittently with a time interval of 3-5 days, and the animals were fed about 20 hours before the experiments. They were then kept in standing position, being loosely fixed to a simple frame made of metal pipes.

The motility of the loops was recorded in the isometric condition. As shown in Fig. 1, Condom-balloon $(B a)$ with a diameter of $3 \mathrm{~cm}$ and filled with water warmed to the body temperature was introduced into the lumen of the loop, being

\footnotetext{
1 福原 武, 難波良司, 椎名 宏.
} 


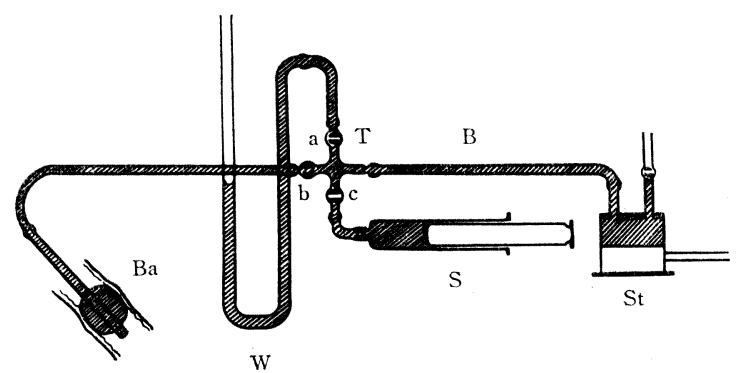

FIG. 1 Scheme Illustrating the Experimental Arrangement for Recording the Motility of Thiry-Vella Loop

$W$, water-manometer; $T$, trifurcated glass tube; $a, b$ and $c$, stop cocks; $S$, syringe; $B a$, condom-balloon; $V$, vinyl tube; $B$, thick rubber tube; $S t$, strain gauge pressure tranducer

connected by means of thick rubber tubes $(B)$ and a trifurcated glass tube $(T)$ provided with stop cocks to the syringe $(S)$ of $10 \mathrm{ml}$ capacity, a water-manometer $(W)$ and the strain gauge pressure transducer $(S t)$ (San'eisokki Co.). Firstly turning the stop cocks appropriately, the balloon, syringe and water-manometer were connected to each other. Observing the scale of the water-manometer, some amount of water was then pressed out of the syringe into the balloon and watermanometer, until the diastolic presssure in the balloon reached about $10 \mathrm{~cm} \mathrm{H}_{2} \mathrm{O}$, and lastly the cocks were turned in such a way that the balloon was connected to the transducer. The change of resistance of the strain gauge installed in the transducer produced in the bridge-circuit the electric disturbance which was amplified electronically and recorded on San'ei pen-recorder. Referring to the calibration curve, both the diastolic (or minimal) and systolic (or maximal) pressure of individual contractions were calculated in terms of water column.

The drug used was the solution containing TTFD which had been offered from Takeda Pharmaceutical Industry Ltd. It was injected at the rate of $5 \mathrm{mg} / \mathrm{ml}$ at the region close to the ankle into the lateral saphenous vein. Pentobarbital sodium (Abott) was used to study its influence upon the action of TTFD.

\section{RESULTS}

\section{Effect of TTFD Administered Intravenously}

As for the tonicity of the dog small intestine in the resting and active states some difference had been found by Hukuhara et al. (5) between the normal and decentralized loops. However, under the conditions of the present experiments no essential difference was observed in the motility and the action of the drug used between the two loops.

In the decentralized loop individual contractions appeared with a regular rhythm, the period being in the mean 4.2 seconds. They slightly varied in their strength from each other, and furthermore, they made an undulation with a time interval of about 40 seconds. The diastolic intraluminal pressure was maintained 
practically constant, being measured in the mean at $10 \mathrm{~cm} \mathrm{H}_{2} \mathrm{O}$, and the systolic pressure was estimated at $44.0 \pm 7.25 \mathrm{~cm} \mathrm{H}_{2} \mathrm{O}$ from 50 successive contractions (Fig. 2A).

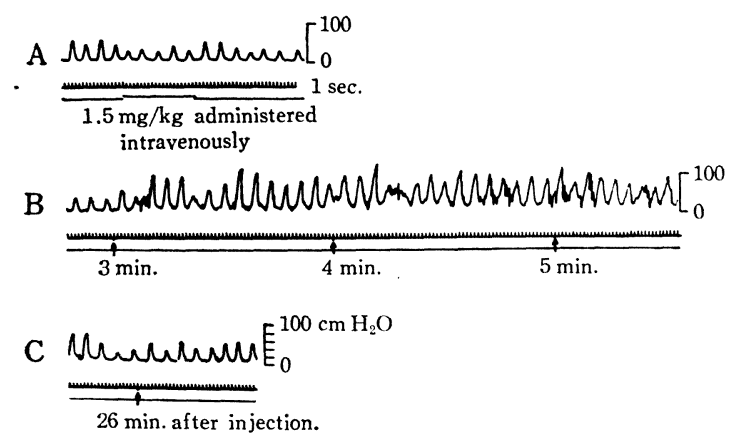

FIG. 2 Effect of TTFD upon the Motility of the Dog Jejunal Loop May 20, 1963. Dog (令), $10.5 \mathrm{~kg}$. Decentralized loop. In each curve from above downwards the isometric contraction, time in seconds and signal are indicated. In $A$ the signal indicates the moment of the intravenous injection of $1.5 \mathrm{mg} / \mathrm{kg}$ of TTFD. Three minutes after the injection a remarkable excitatory effect was produced $(B)$. This state lasted for about 25 minutes to be then restored to the normal $(C)$.

About some ten seconds to 3 minutes after administering $1.5 \mathrm{mg} / \mathrm{kg}$ of TTFD intravenously individual contractions became rapidly powerful to reach the period of maximal strength which persisted for 3 to 4 minutes. In this period the time interval of contractions was shortened to about 3.8 seconds, the diastolic pressure rose to $15 \mathrm{~cm} \mathrm{H}_{2} \mathrm{O}$ and the systolic one was increased to $88.8 \pm 18.39 \mathrm{~cm} \mathrm{H}_{2} \mathrm{O}$, twice as high as that observed before the administration of the drug. Following this period, the excitatory state gradually subsided until it was restored to the normal about 25 minutes after the injection of the drug.

Inasmuch as when the animal was anesthetized with $25 \mathrm{mg} / \mathrm{kg}$ pentobarbital sodium, the intestinal motility fell into a remarkable depression which persisted for 2 hours or more, the intravenous administration of $1.5 \mathrm{mg} / \mathrm{kg}$ of TTFD produced

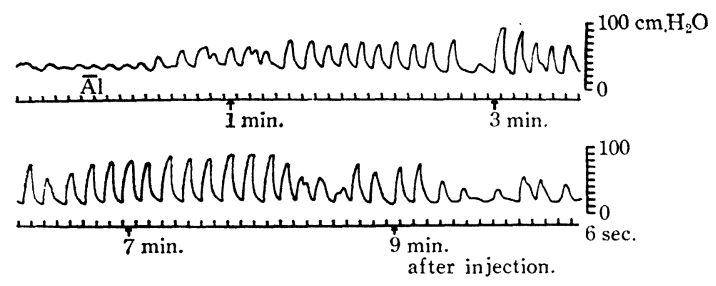

FIG. 3 Effect of TTFD upon the Motility of the Jejunal Loop', of the Dog Anesthetized

Feb. 11, 1965. Dog (ㅇ), $9.0 \mathrm{~kg}$. Normal loop. Explanations of the curves are the same as in Fig. 1. The animal was previously anesthetized with $25 \mathrm{mg} / \mathrm{kg}$ Na-pentobarbital; the motility of the loop was remarkably depressed. When at $A l 1.5 \mathrm{mg} / \mathrm{kg}$ TTFD was injected intravenously, the motility was remarkably excited. 
an excitatory effect largely similar in its degree and duration to that observed on the non-anesthetized animal. The example is shown in Fig. 3. The results thus revealed that this amount of pentobarbital sodium had hardly any remarkable influence upon the excitatory action of TTFD on the intestinal motility.

\section{Effect of T'TFD Applied to the Mucosa}

When $1 \mathrm{ml}$ of TTFD solution was cerefully introduced in to the lumen of the decentralized loop close to its anal or oral end, the mucosal intrinsic reflex was elicited, resulting in remarkable effects, an excitation orally to and inhibition anally to the spot where the drug was applied. The example is shown in Fig. 4. It had been studied in detail by Hukuhara et al. $(1,2)$ that the mucosal intrinsic reflex played an important role to regulate the intestinal motility.

A
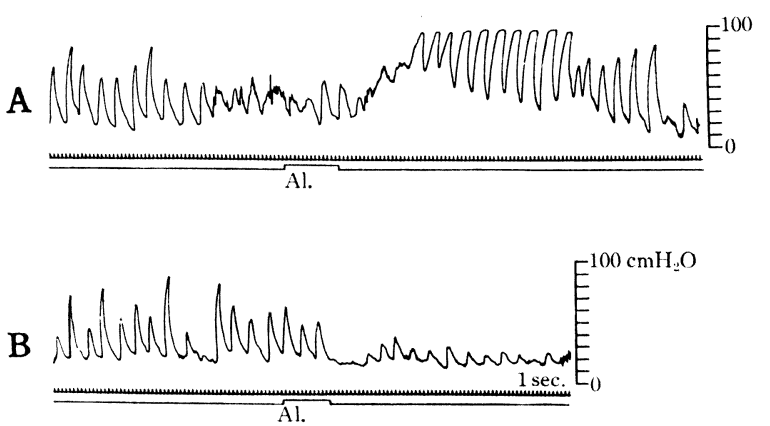

Fic. 4 Effect of T'TFI Applied to the Mucosa upon the Motility of the Je junal Loop

Feb. 16, 1965. Dog (f), $9.0 \mathrm{~kg}$. Decentralized loop. Explantations of the curves are the same as in Fig. 1. The motility of the loop was excited (A) or depressed $(B)$ according as $1 \mathrm{ml}$ of TTFD solution was applied $(A l)$ to the mucosa of the loop close to its anal or oral end.

\section{Effect of TTFD upon the Motility of the Loop Devoid of Intramural} Nerious Elements

Upon the loop whose intramural ganglion cells had been completely destroyed no effect of TTFD was observed as shown in Fig. 5.

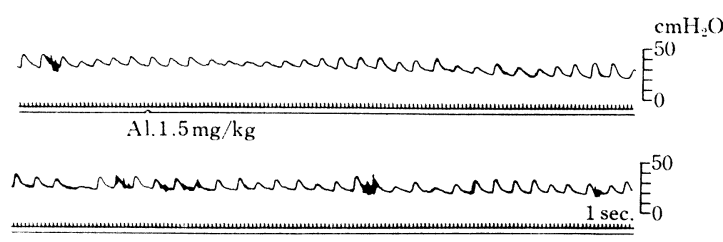

Frg. 5 Effect of TTFD upon the Motility of the Dog Jejunal Loop Devoid of Nervous Elements

Feb. 16, 1965. Dog (ㅇ), $9.0 \mathrm{~kg}$. The experiment was performed 20 months after the operation for destroying the intramural nervous elements. The intravenous administration of TTFD had no effect upon the motility of the loop. 


\section{DISCUSSION}

The present experiments revealed that in the non-anesthetized animal provided with Thiry-Vella loops the action of TTFD on the intestinal motility was much more effective and lasting longer than that observed in the acute experiments. And from the results described above it may be presumed that the site of action of the drug is as follows: Firstly, the drug exerts no action on the intestinal muscle, because it had no effect on the intestine devoid of nervous elements. Secondly, the drug reflexly produces the excitation of the intramural ganglion cells, because it elicits the mucosal intrinsic reflex by stimulating the intestinal mucosa. Thirdly, the drug can directly exert an excitatory action upon the intramural ganglion cells, because it produces an excitation of the intestinal motility, when it is administered intravenously. The evidences that the drug might in the main act upon the nervous elements residing in the intestinal wall were also obtained in the experiments carried out on the isolated small intestine of various mammals, and their results will be reported later.

\section{SUMMARY}

1. On non-anesthetized dogs provided with the normal, decentralized and aganglionic Thiry-Vella jejunal loops the effect of thiamine tetrahydrofurfuryldisulfide (TTFD) upon the intestinal motility was studied.

2. On the normal and decentralized loops the intravenous administration of 1.5 $\mathrm{mg} / \mathrm{kg}$ of TTFD produced a slight rise of tone and a remarkable increase of the amplitude of rhythmic contractions for about 25 minutes.

3. In the animal anesthetized with $25 \mathrm{mg} / \mathrm{kg}$ of pentobarbital sodium the drug also increased the motility of the normal and decentralized loops as remarkably as in the non-anesthetized animal.

4. The drug exerted no action upon the aganglionic loop.

5. A small amount $(1 \mathrm{ml})$ of $5 \mathrm{mg} / \mathrm{kg}$ TTFD solution which had been carefully introduced into the intestinal lumen, stimulated the mucosa to elicit the mucosal intrinsic reflex the effect of which consisted of an excitation above and inhibition below the stimulated spot.

6. The probable site of action of the drug was discussed.

\section{REFERENCES}

1. Hukuhara, T., Yamagami, M. and Nakayama, S., Jap. J. Physiol. 8, 9 (1958)

2. Hukuhara, T., Nakayama, S. and Sumi, T., Jap. J. Phsiol. 9, 406 (1959).

3. Hukuhara, T., Sumi, T. and Kotani, S., Jap. J. Physiol 11, 281 (1961).

4. Hukuhara, T., Kotani, S. and Sato, G., Jap. J. Physiol. 11, 635 (1961).

5. Hukuhara, T., Kotani, S. and Sato, G., Jap. J. Physiol. 12, 348 (1962).

6. Nanba, R. and Nakayama, S. Vitamins 22, 142 (1960).

7. Nakayama, S. and Nanba, R. Vitamins 26, 235 (1963). 